\title{
CONSIDERAÇÕES SOBRE O PRINCÍPIO DE INDUÇÃO FINITA À LUZ DA DEFINIÇÃO DE QUANTIFICADOR UNIVERSAL
}

\section{ARTIGO ORIGINAL}

PEREIRA, Olavo de Carvalho ${ }^{1}$

PEREIRA, Olavo de Carvalho. Considerações sobre o princípio de indução finita à luz da definição de quantificador universal. Revista Científica Multidisciplinar Núcleo do Conhecimento. Ano 05, Ed. 01, Vol. 01, pp. 53-57. Janeiro de 2020. ISSN: 2448-0959, Link de acesso: https://www.nucleodoconhecimento.com.br/matematica/principio-de-inducao

\section{RESUMO}

O artigo mostra que o Princípio de Indução Finita, da maneira como está definido, sobretudo nos livros citados, não produz indução alguma.

Palavras-Chave: Indução Finita, princípio.

\section{INTRODUÇÃO}

O presente artigo tem o objetivo de rever o princípio de indução finita, à luz do que se depreende da definição de quantificador universal, no intuito de estabelecer a real situação a ser considerada.

${ }^{1}$ Graduação - Bacharelado em Matemática pela Universidade de Brasília. 


\subsection{QUANTIFICADOR UNIVERSAL E O PRINCÍPIO DE INDUÇÃO FINITA}

O quantificador universal é utilizado quando queremos nos referir a todos os elementos de um conjunto, seja ele o conjunto dos naturais, dos inteiros, dos racionais, ...., ou um conjunto qualquer, $\mathrm{X}$.

Seu símbolo é $\forall$ e significa "para todo", "qualquer que seja", etc.

Por exemplo, quando dizemos "para todo $\mathrm{k}$ pertencente ao conjunto dos números naturais" isto significa "para todo número natural k"; isto é, para todo número natural aqui designado genericamente pela letra k; significa, portanto, que $\mathbf{k}$ representa todos os números naturais e que, dessa forma, pode ser identificado com o próprio conjunto dos números naturais, isto é, $\mathrm{k}=\mathrm{N}$.

Quando utilizamos o quantificador universal, por exemplo, $\forall \mathrm{k} \in \mathrm{N}$, pelo fato do $\mathrm{k}$ representar todo e qualquer número natural, a expressão $k+1$ fica sem sentido, pois, seria equivalente a $\mathrm{N}+1$ (o conjunto de todos os números naturais acrescido de uma unidade).

Outro exemplo: quando dizemos, "para todo k pertencente ao conjunto dos números naturais, $2 \mathrm{k}$ é par", significa que $\mathrm{k}=\mathrm{N}$ e $2 \mathrm{k}=2$ multiplicado por cada número natural, portanto, equivalente a $2 \mathrm{~N}$, que representa todos os números pares.

Situação diferente é quando dizemos "seja k um número natural" ou "dado k $\in$ N", em que o número k é separado, é destacado do conjunto dos naturais e representa apenas um elemento daquele conjunto, por exemplo, seja $k=5$ (o 5 foi destacado do conjunto dos números naturais).

Quando destacamos o número natural como na expressão "seja $k \in \mathrm{N}$ ", faz sentido falarmos em $k+1$, isto é, faz sentido falarmos do natural $k+1$ sucessor do natural $k$.

O significado do quantificador universal nem sempre tem sido utilizado de forma correta, acarretando inconsistência lógica. 
Identificamos sua utilização na definição do princípio de indução finita e analisamos uma consequência lógica imediata.

Vejamos algumas versões.

Filho (1992) define o princípio de indução finita da seguinte forma:

"Seja $\mathrm{S}$ um subconjunto do conjunto $\mathrm{N}$ dos inteiros positivos (conjunto dos números naturais) que satisfaz as duas seguintes condições:

- 1 pertence a S;

- Para todo inteiro positivo k, (portanto, para todo número natural $k$ ), se $k$ pertence a $S$, então $k+1$ pertence a S.

Nestas condições, $\mathrm{S}$ é o conjunto $\mathrm{N}$ dos inteiros positivos: $\mathrm{S}=\mathrm{N}$. (p.34)"

Analisando a definição acima, no item (2) temos o quantificador universal do conjunto $\mathrm{N}$ dos naturais. A expressão "Para todo inteiro positivo k", significa que k representa todos os naturais, o conjunto completo dos números naturais, e, portanto, pode ser identificado com o conjunto dos naturais, isto é, $\mathrm{k}=\mathrm{N}$. Continuando . . . se k pertence a $\mathrm{S}$, isto significa que todo número natural pertence a $\mathrm{S}$, e, com isso, o conjunto $\mathrm{N}$ dos naturais está todo contido no conjunto $\mathrm{S}$. Como $\mathrm{k}$ já representa todo e qualquer número natural, a expressão " $k+1$ " fica sem sentido no contexto da definição, pois seria equivalente a $\mathbf{N + 1}$ (o conjunto de todos os números naturais acrescido de uma unidade). Portanto a expressão "k+1" não tem razão de ser.

Em Lima (1978) o princípio de indução finita é definido assim:

"Se $\mathrm{X}$ contido em $\mathrm{N}$ (conjunto dos números naturais) é um subconjunto tal que 1 pertence a $X$ e, para todo $n$ (natural) pertencente a $X$ tem-se também o sucessor de $n,(n+1)$, pertencente a $X$, então $X=N$. (p. 26)"

Analisando esta definição identificamos o quantificador universal do conjunto $X$ na expressão "para todo $\mathrm{n}$ (natural) pertencente a X" onde $\mathrm{n}$ representa todos os 
elementos de $X$, o conjunto $X$ completo, e, portanto, $n=X$. Sendo assim, da mesma forma que na definição anterior, a expressão $n+1$ em nada acrescenta em relação aos elementos de $\mathrm{X}$, uma vez que $\mathrm{n}$ já representa todos os elementos de $\mathrm{X}$. Neste caso, $\mathrm{n}+1$ significaria $X+1$, e, por isso, ficaria sem sentido no contexto da definição.

Na definição de Filho (1992), chega-se à conclusão de que $\mathrm{S}=\mathrm{N}$, simplesmente porque se supôs $\mathrm{S}$ contido em $\mathrm{N}$ e $\mathrm{N}$ contido em $\mathrm{S}$, e não porque se utilizou de um mecanismo de sucessão de elementos que expandiu o conjunto $S$ até identificá-lo com o conjunto dos naturais; nela o item (1) está contido no item (2), uma vez que k é o quantificador universal de $\mathrm{N}$, contendo, portanto, o elemento 1.

Na definição do conjunto X, contido em Lima (1978), temos apenas que X está contido em N, pois a inclusão inversa não foi conseguida pela estrutura apresentada. Sendo assim, de forma alguma pode-se chegar à conclusão de que $\mathrm{X}=\mathrm{N}$.

Vejamos mais um exemplo.

lezzi e Murakami (1991) assim definem o Princípio de Indução Finita:

“Uma proposição $P(n)$, aplicável aos números naturais $n$, é verdadeira para todo $n \in N, n \geq \omega$, quando

$\left.1^{\circ}\right) P(\omega)$ é verdadeira, isto é, a propriedade é válida para $n=\omega, e$

$\left.2^{\circ}\right)$ Se $k \in N, k \geq \omega$ e $P(k)$ é verdadeira, então $P(k+1)$ também é verdadeira. (p. 53 a 54)"

Neste caso a situação é mais restrita ainda, pois não temos o quantificador universal na estrutura da definição, isto é, em $2^{\circ}$ ) lemos "Se k $\in$ N", ou seja, o k representa um número qualquer que foi destacado do conjunto dos números naturais $\mathrm{e}$, por isso, $P(k)$ e $P(k+1)$ representarão apenas dois números, não sendo possível se fazer uma indução.

Do exposto, conclui-se que essas definições nada acrescentam em termos matemáticos, pois o "Princípio de Indução Finita”, da maneira como está definido 
nos exemplos citados, não produz indução alguma, uma vez que, com a estrutura lógica apresentada, o quantificador universal do conjunto dos naturais, ou de um dado conjunto $X$, já representa os elementos desses conjuntos, não sendo necessário, nem possível, utilizar-se de um sucessor de elementos dos conjuntos dados para expandilos até o conjunto dos naturais.

\section{CONCLUSÃO}

No exposto mostramos a não existência do princípio de indução finita, da maneira como está definido nos livros citados.

A tese se baseou na definição de quantificador universal.

Relatamos essa observação na intenção de que tal princípio, caso possua uma estrutura lógica que respalde sua existência, possa ela constar em livros que se destinam ao ensino da matemática elementar.

\section{REFERÊNCIAS}

FILHO, Edgar de Alencar. Teoria Elementar dos Números, 3ª̣ edição, 1992.

IEZZI,Gelson e MURAKAMI, Carlos. Fundamentos de Matemática Elementar, Volume $1,1991$.

LIMA, Elon Lages. Curso de Análise, vol. 1, 1978.

Enviado: Novembro, 2019.

Aprovado: Janeiro, 2020. 